\title{
Cesarean Scar Hysterotomy: Assessment by Three-dimensional Transvaginal Ultrasound Scan
}

1JM Troyano, ${ }^{2} \mathrm{MT}$ Clavijo, ${ }^{3} \mathrm{I}$ Martinez-Wallin, ${ }^{4} \mathrm{~A}$ Molina Betancor, ${ }^{5} \mathrm{M}$ Alvarez de la Rosa, ${ }^{6} \mathrm{Al}$ Padilla, ${ }^{7} \mathrm{José} \mathrm{Bajo-Arenas}$

\begin{abstract}
Objective: The combined study of two-dimensional (2D) and three-dimensional (3D) sonographic records may be useful to diagnose wound dehiscence from hysterotomy and forecast the well-being of future gestations. In that respect, irregular cicatrization patterns can be identified from the early puerperium over the whole postparturition recovery period, and may encourage the need for further cesarean in new pregnancies to come.
\end{abstract}

Subjects and Methods: A random sample of 42 female patients were subjected to transvaginal sonographic exploration at three sampling times, namely 4 days, 4 months, and 1 year following hysterotomy. All of these women recovered successfully from their cesarean and were discharged from hospital 5 days after parturition.

The $2 \mathrm{D}$ and $3 \mathrm{D}$ surveys were subsequently undertaken at each of the three study times. Four days after surgery, the 2D ultrasound scan aimed at evaluating the early evolution of the uterine scar. On the contrary, 3D echographies were implemented frame-to-frame, in a transverse direction, from the right to left sides of the uterus.

Results: The 3D sonographic records from those dehiscent wounds displayed at this time a wide, irregular hypoechogenic area crossed over by linear structures representing the suture material (Vycril). Such a record was called a "shark bite" pattern.

The latter puerperal dehiscence pattern persisted in the isthmic region for 4 months and 1 year after delivery. It consistently featured a notch between the scar borders that run perpendicular to the complete extent of the internal myometrium layer and bordered the anterior uterine wall.

By considering the length of the hysterotomy-derived notch over the whole study period, two types of scars could be differentiated through $2 \mathrm{D}$ sonographic surveys, scar notches $>2 / 3$ $(n=9)$ or $\leq 1 / 3(n=4)$ of the total scar lengt. Six of the 13 wounddehiscent women monitored in this study became pregnant within 2 years after their former cesarean.

All were subjected to a second hysterotomy, before which an in situ examination of the previous uterine scar could be made.

Early puerperal ultrasound scan focusing on hypoechogenic areas across the borders of hysterotomy-derived scars under suturing pressure must be undertaken by means of 2D transvaginal ultrasound scan, with the bonus that such exploration can be extended through several months to a 1 year period

\footnotetext{
${ }^{1,7}$ Professor, ${ }^{2-4}$ Specialist, ${ }^{5,6}$ Associate Professor

1-3,5,6 Universidad de La Laguna, Hospital Universitario de Canarias

${ }^{4}$ Hospital Universitario Nuestra Señora de la Candelaria

${ }^{7}$ Universidad Autónoma de Madrid
}

Corresponding Author: JM Troyano, Professor, Universidad de La Laguna, Hospital Universitario de Canariasm, e-mail: jtroyanol@sego.es; jtroyano@ull.es after surgery. The extent of dehiscent myometrium areas and the depth of the notch remaining between the serose and the cervical channel of the stigma can be used as reliable indicators for defective cicatrization processes and should be used as background information aiding in future gestations.

The 3D transvaginal ultrasound scan provides the practitioner with thorough records of myometrial failure and enhances the morphological study of iatrogenic pathologies originating from cesarean surgery.

The state and extent of healed $v s$ failing cicatrization areas can be easily assessed by means of $3 \mathrm{D}$ transvaginal ultrasound scan.

Keywords: Cesarean section, Cicatrix, Pregnancy, Three dimensional ultrasound, Wound healing.

How to cite this article: Troyano JM, Clavijo MT, MartinezWallin I, Molina-Betancor A, Alvarez-de-la-Rosa M, Padilla Al, Bajo-Arenas J. Cesarean Scar Hysterotomy: Assessment by Three-dimensional Transvaginal Ultrasound Scan. Donald School J Ultrasound Obstet Gynecol 2017;11(1):82-87.

Source of support: Nil

Conflict of interest: None

\section{INTRODUCTION}

Hysterotomy-made scars are a key factor for assessing further gestations in the same patient, and so need to be monitored from the early puerperium through a whole year period following surgery. Other monitoring factors involve placenta previa, placenta accreta, ectopic cervical gestation, or uterine rupture both on parturition and at rest.

Two-dimensional (2D) transvaginal ultrasound scan has proved a successful method in the detection of scar failures of the myometrium early in the puerperal period and afterwards, or in routine sonographic exploration. Furthermore, three-dimensional (3D) ultrasound scan facilitates the monitoring of hysterotomy-made scars whereby total areas and depths of healed vs failing myometrium tissue can be quantified.

The combined study of 2D and 3D sonographic records may be useful to diagnose wound dehiscence from hysterotomy and forecast the welfare of future gestations. In that respect, irregular cicatrization patterns can be identified from the early puerperium over the whole postparturition recovery period, and may encourage the need for further cesarean in new pregnancies to come.

\section{ECOGRAPHY SURVEY OF HYSTEROTOMY-MADE SCARS}

A number of requirements must be met in hysterotomy practice in order to avoid failed cicatrization patterns in 


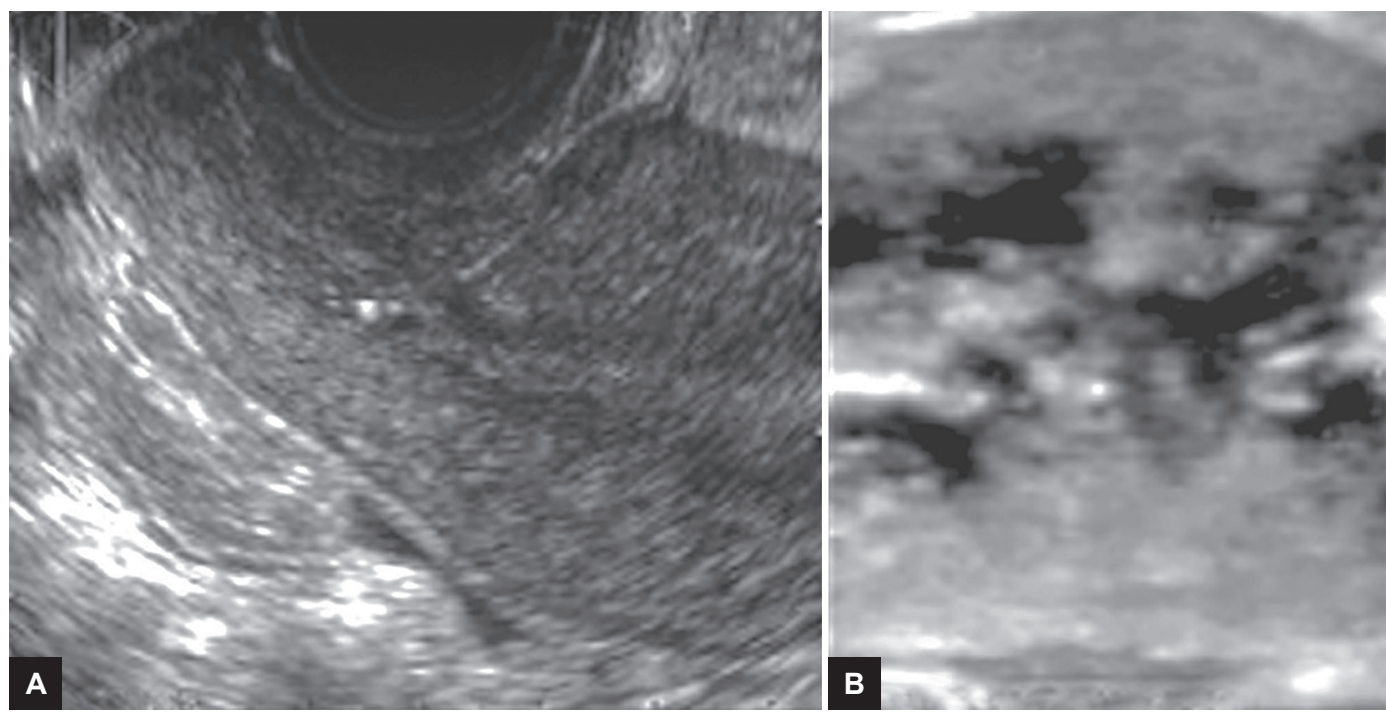

Figs $1 \mathrm{~A}$ and $\mathrm{B}$ : Isthmic area between the cervix and corpus uteri, which is the target of transverse segmentary hysterotomy
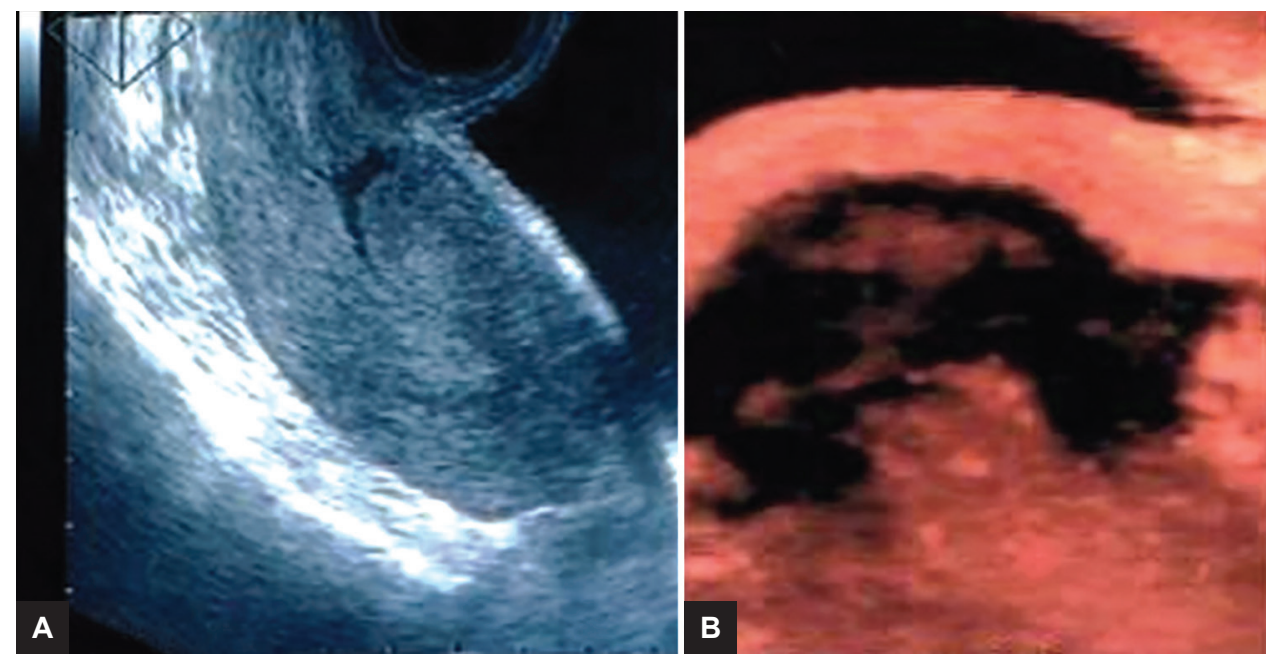

Figs 2A and B: Hysterotomy incision into the myometrial layer located above the uterine segment. This is the major factor bringing about wound dehiscence problems

future gestations, e.g., postparturition or resting uterine rupture, pracenta previa or accreta, or even abruptio placentae. $^{1-3}$

The main requirement consists of the hysterotomy being applied to the band of the uterine segment, which is frontier between the cervix and the uterus, the so-called transverse, segmentary hysterotomy (Figs 1A and B). The contours of this uterine segment become faint as the cervix grows thin and is embodied by the corpus uteri with the progress of labor.

Hysterotomy is facilitated in three ways by the uterine segment thinning out during parturition, i.e., bleeding is reduced, the surgical sutura becomes straightforward, and the cicatrization process is aided. In contrast, inexperience by the practitioner or unexpected problems in labor may result in hysterotomy incisions into the anterior myometrial wall, some 1 to $2 \mathrm{~cm}$ above the target uterine segment (Figs 2A and B).
The latter may be called transverse, corporal incisions, and compromise a relatively thick layer of myometrium that may reach endometrium tissue between the two scar borders.

Though frequently unnoticed by the surgeon, transverse, corporal incisions are the main factor precluding labor in future gestations where they may lead to conditions like uterine tearing, wound dehiscence, or uterus dysdynamogenesis. A total of $30 \%$ of pregnant women presenting normal cephalopelvic dimensions and following a former delivery subjected to transverse, corporal hysterotomy could not avoid a further cesarean due to impoverishment of uterine dynamics. ${ }^{1,2,4}$ This may be due to the fact that myometrium cicatrization and fibrosis above the uterine segment prevent the transmission of electric signals in the inferior third of the uterus, so interfering with the gradual dilation and effacing of the cervix. 


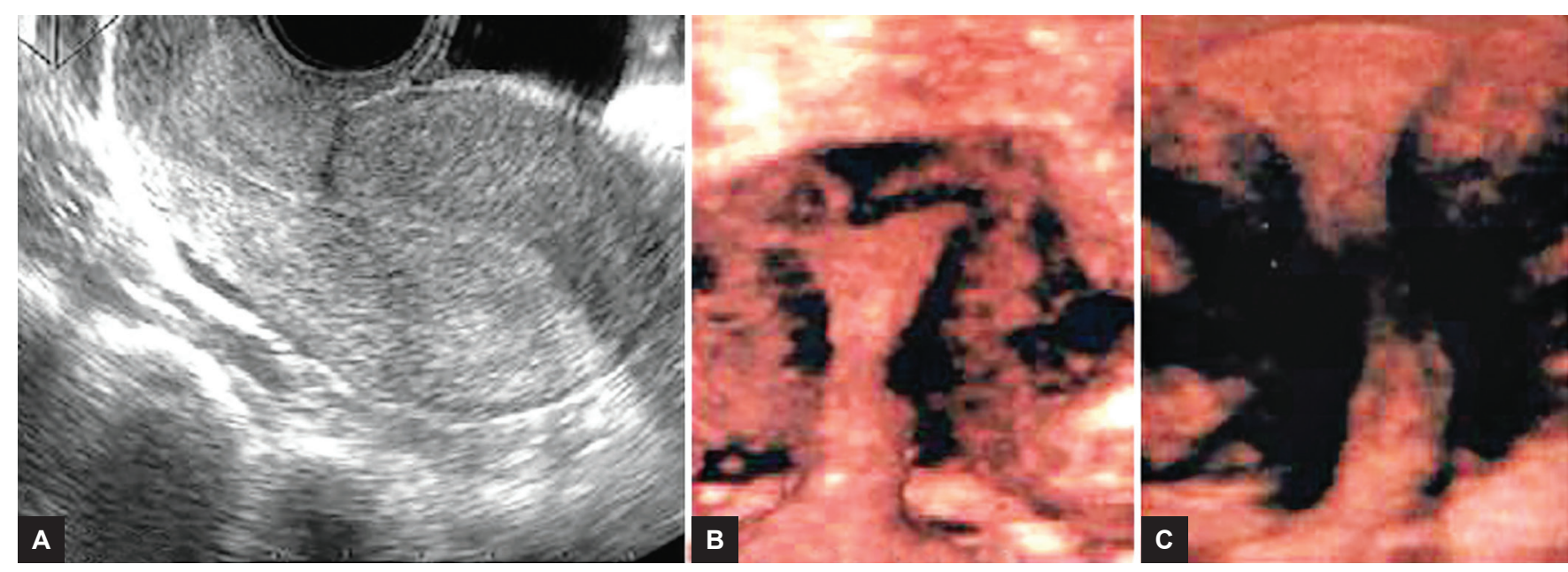

Figs 3A to C: Normal scar 4 months following cesarean surgery: (A) 2D ultrasound; (B) endometrial cavity and segmentum uteri integrity by $3 D$ ultrasound $B$ and $(C)$ failure scar in endometrial cavity near segmentum uteri, 3D ultrasound

Futhermore, hysterotomy-made wound dehiscence has been often associated with pelvic pain, nonspecific dysuria, and anomalous uterine bleeding in women with previous cesarean section. ${ }^{5}$

Whatever the hysterotomy strategy being applied, transvaginal ultrasound scan represents a complementary and useful tool for assessing and monitoring uterine scars from the puerperium onwards. Scar borders manifest themselves in an echogenic line going perpendicular to the axis between the peritoneal border and the endocervical channel, ornated by the echogenic marks of the stitch material (Figs $3 \mathrm{~A}$ to $\mathrm{C}$ ). From 4 months to 1 year after hysterotomy in patients having a fit recovery from surgery, the uterine scar may become completely unnoticeable by ultrasound scan or at most translate into a little echogenic area in the posterior wall of the bladder.

On the contrary, extensive hypoechogenic areas between the borders of hysterotomy-made scars are already visible only 4 days following cesarean surgery, and are indicative of failed cicatrization that can be further confirmed 4 months and 1 year after surgery. This results in boomerang-shaped scars (scar stigma) permanent over the rest of the women's life (Figs 4A to C).

To enhance the welfare of future gestations and deliveries, scar stigma must be characterized by quantifying both the hysterotomy-affected myometrium area (in a transverse direction) and the depth of the scar notch between the uterine surface and the endocervical channel. This can be fairly easily attained by means of 3D transvaginal ultrasound scan, where the estimation for ratios of healed to failed myometrium cicatrization percentages is straightforward (Figs 5A and B).

\section{MATERIALS AND METHODS}

Between 2011 and 2015 of 42 female patients were subjected to transvaginal sonographic exploration at three sampling times, namely 4 days, 4 months, and 1 year following hysterotomy. All of these women recovered successfully from their cesarean and were discharged from hospital 5 days after parturition.

Explorations were carried out by means of an ALOKA 5000 Prosound and Voluson 730 Expert (GE Medical

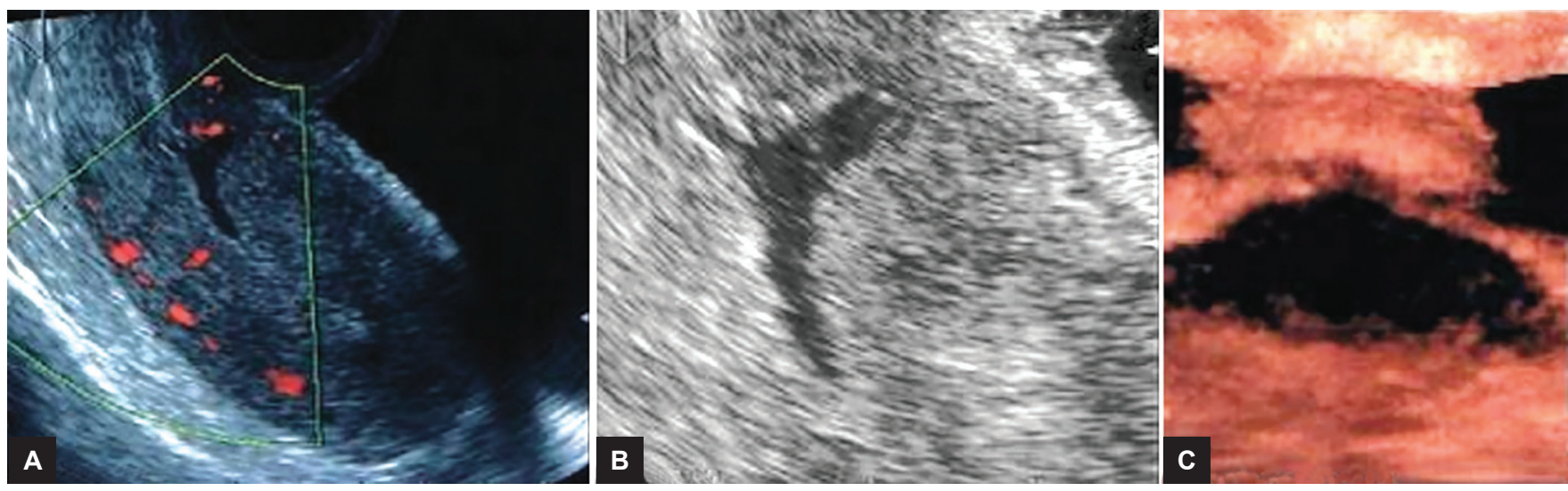

Figs 4A to C: Extensive hypoechogenic areas between the borders of hysterotomy (4 days following cesarean surgery). This results in "boomerang-shaped" scars (scar stigma) permanent over the whole of the women's life 


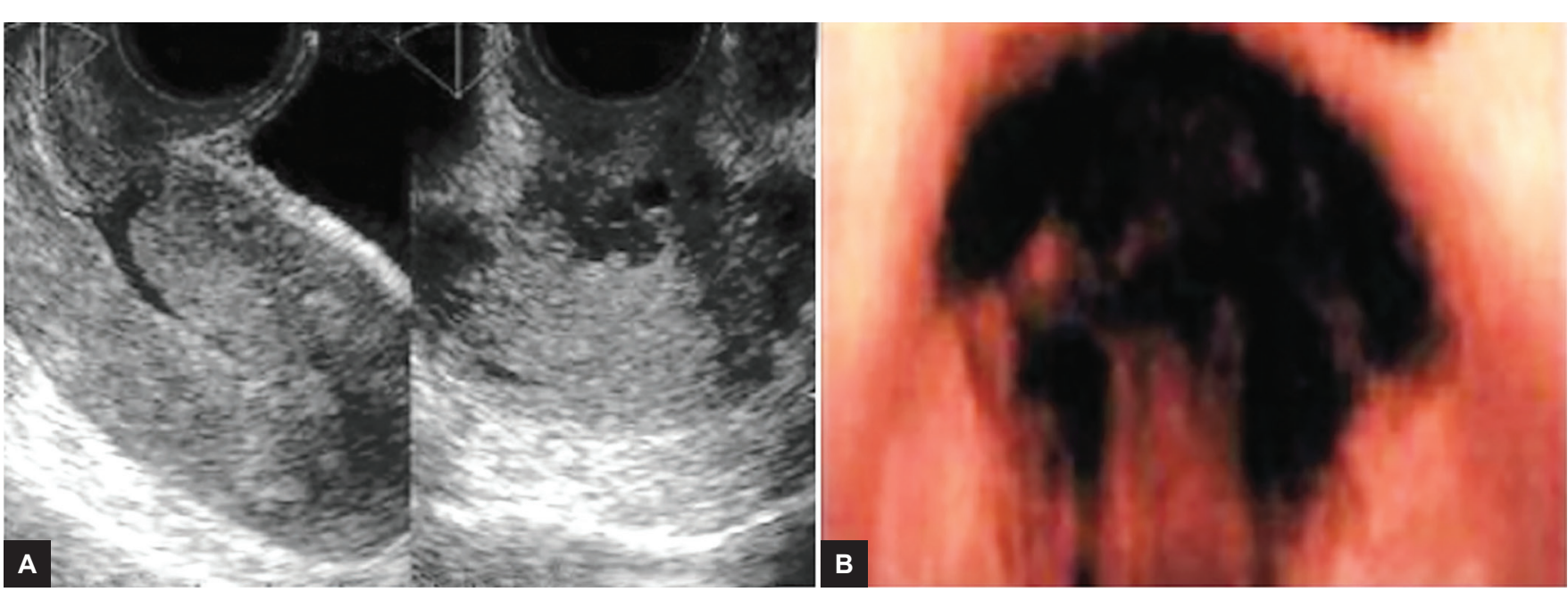

Figs 5A and B: Scar stigma must be characterized by quantifying both the hysterotomy-affected myometrium area (in transverse direction). This can be fairly easily attained by means of 3D transvaginal ultrasound scan

Systems. Kretztechnike GmbH, Zipf, Austria). The 2D and 3D scans were subsequently undertaken at each of the three study times. Four days after surgery, the 2D ultrasound scan aimed at evaluating the early evolution of the uterine scar. On the contrary, 3D ultrasound scans were implemented frame-to-frame, in a transverse direction, from the right to left sides of the uterus.

\section{RESULTS}

Four days after each hysterotomy was undertaken, incomplete closure over two-thirds of the scar length was observed in 14 out of the 42 women explored. This was deemed to be a sign of wound dehiscence along most of the internal myometrium layer. The 3D sonographic records from those dehiscent wounds displayed at this time a wide, irregular hypoechogenic area crossed over by linear structures representing the sutura material (Vycril). Such a record was called a "shark bite" pattern (Figs 6A to C).

The latter puerperal dehiscence pattern persisted in the isthmic region for 4 months and 1 year after delivery. It consistently featured a notch between the scar borders that run perpendicular to the complete extent of the internal myometrium layer and bordered the anterior uterine wall (Table 1).

By considering the length of the hysterotomy-derived notch over the whole study period, two types of scars could be differentiated through $2 \mathrm{D}$ sonographic surveys, i.e., scar notches $>2 / 3(n=9)$ or $\leq 1 / 3(n=4)$ of the total scar length (Table 2). Notch depths between scar borders can be also seen in Table 2.

No sonographic patterns could be observed in wound-dehiscentless women $(n=29)$ by neither of the sonographic methods employed throughout the study period, with little echogenic areas being rarely detected in the isthmic region.

Table 1: Uterine scar patterns as surveyed by transvaginal ultrasound scan exploration after hysterotomy $(n=42)$

\begin{tabular}{llll}
\hline & \multicolumn{3}{c}{ Postcesarean period } \\
\cline { 2 - 4 } & 4 days & 4 months & 1 year \\
\hline Dehiscent scars $(\mathrm{n}=13)$ & Yes & Yes & No \\
Dehiscentless scars $(\mathrm{n}=29)$ & No & No & No \\
\hline
\end{tabular}

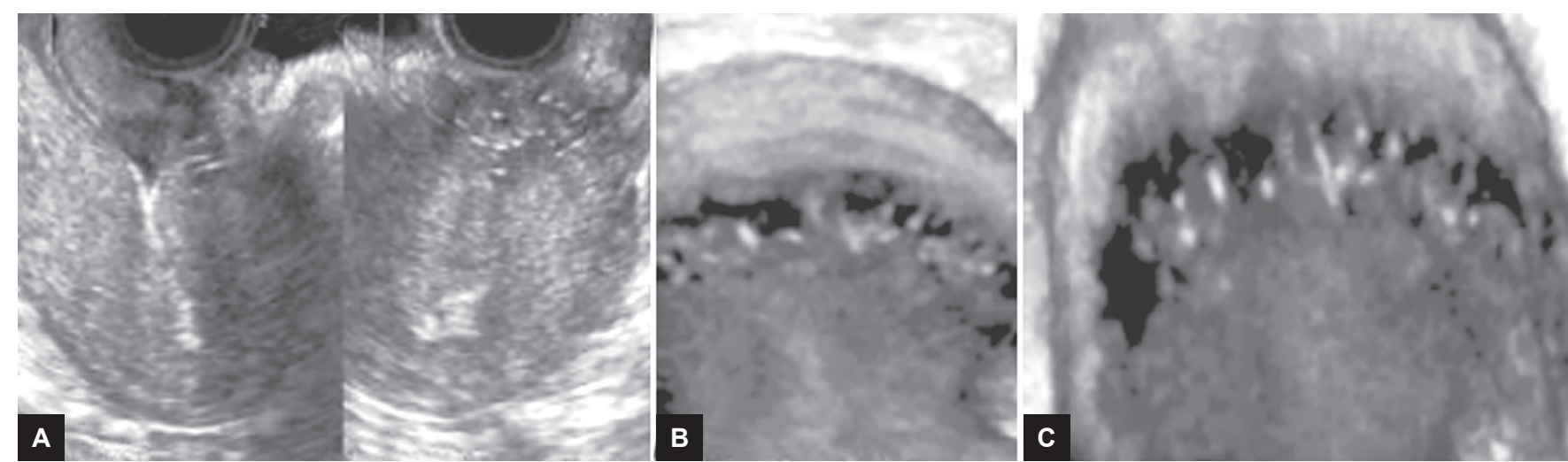

Figs 6 A to C: Incomplete closure over two-thirds of the scar length by 3D sonographic records. This is a typical image of hysterotomy dehiscence. Irregular hypoechogenic area crossed over linear structures representing the suture material (Vicryl). Such a record was called a "shark bite" 
Table 2: The 2D sonographic patterns with details of dehiscence extent originating from hysterotomy $(n=13)$

\begin{tabular}{lllll}
\hline & \multicolumn{4}{c}{ Scar notch } \\
\cline { 2 - 5 } & \multicolumn{3}{c}{4 months } & 1 year \\
\hline $\begin{array}{l}\text { Notch length relative } \\
\text { to total scar length }\end{array}$ & Depth & Wideness & Depth & Wideness \\
\hline $2 / 3(\mathrm{n}=9)$ & $9 \mathrm{~mm}$ & $6 \mathrm{~mm}$ & $7 \mathrm{~mm}$ & $4 \mathrm{~mm}$ \\
$1 / 3(\mathrm{n}=4)$ & $3 \mathrm{~mm}$ & $4 \mathrm{~mm}$ & $3 \mathrm{~mm}$ & $4 \mathrm{~mm}$ \\
\hline
\end{tabular}

Table 4: Pathological scars in the isthmic region in women $(n=317)$ subjected to single hysterotomy in the previous 6 years

\begin{tabular}{ll}
\hline Dysmenorrhea & 195 \\
Spotting & 15 \\
Anomalous uterine bleeding & 31 \\
Painful sexual intercourse & 61 \\
Menorrhagia & 15 \\
\hline
\end{tabular}

Six of the 13 wound-dehiscent women monitored in this study became pregnant within 2 years after their previous cesarean. All were subjected to a second hysterotomy, before which an in situ examination of the previous uterine scar could be made as shown in Table 3.

In a different study, between 2011 and 2015, a total of 317 women, going through hysterotomy within the previous 6 years and showing ensuing pathological cicatrization in the isthmic region, were subjected to clinical and ultrasound scans. The whole sample of patients displayed an array of pathologies that were not obvious before the cesarean had been carried out (Table 4). Among these pathologies, dysmenorrhea and painful sexual intercourse in younger women, and anomalous uterine bleeding in postmenopause women, were most outstanding, and caused major stress on the patients.

No control group was available for the latter study, but our data strongly suggests that an association between the application of hysterotomy and the occurrence of genital pathologies was possible.

\section{CONCLUSION}

Uterine scar patterns and their related diseases have been recently studied by a number of authors elsewhere, ${ }^{6,7}$ and the adequateness of invasive methods, such as hysterosonography has been proposed. ${ }^{8}$ These methods are 2D; therefore, it is our own view that they cannot provide with accurate estimates for scar length and depth and for wideness of the notch between the two scar borders. Moreover, their application is unfeasible during the early puerperium, and must so be delayed to the late postparturition recovery period or their use confined to routine ultrasound scans when the detection of pathologies may be casual. Early puerperal ultrasound scan focusing on hypoechogenic areas across the borders of hysterotomy-derived scars under suturing pressure must be undertaken by means of 2D
Table 3: Scar patterns from women subjected to a second hysterotomy after the study period $(n=6)$

\begin{tabular}{lrlll}
\hline $2^{a}$ cesarean (100\%) & \multicolumn{3}{l}{ Wound state } \\
\hline No pattern & 4 & Dehiscent & $5^{*}$ Dehiscentless $1^{* *}$ \\
Fetal distress & 1 & \\
Podalic position & 1 & \\
\hline *Scar narrow, retractile, and rigid; ** Scar narrow and fibrous
\end{tabular}

transvaginal ultrasound scan, with the bonus that such exploration can be extended through several months to a 1 year period after surgery.

In fact, scar stigma remains so throughout the patient's life. The extent of dehiscent myometrium areas and the depth of the notch remaining between the serose and the cervical channel of the stigma can be used as reliable indicators for failing cicatrization processes and should be used as background information aiding in future gestations.

The 3D transvaginal ultrasound scan provides the practitioner with thorough records of myometrial failure and enhances the morphological study of iatrogenic pathologies originating from cesarean surgery.

Hysterotomy incisions above the uterine isthmus invariably lead to scar structural failures by 1 year after cesarean has been applied, but can be detected by 4 days postparturition.

The length and wideness of the areas experiencing structural failure are proportional to the distance between the hysterotomy incision and the uterine segment.

Failing cicatrization patterns result from cicatrization involving only the surface layers of the myometrium tissue, with two-thirds of the deeper myometrium layer remaining dehiscent.

The state and extent of healed vs failing cicatrization areas can be easily assessed by means of 3D transvaginal ultrasound scan.

Unlike the measurement of the depth of the scar notch, no reliable spatial references can be used to measure the distance between the surface serose and the peak of the scar notch, so the latter has been excluded from the methodological protocol presented herein.

\section{REFERENCES}

1. Van Han P, Van Dongen PW, Mulder J. Maternal consequences of cesarean section. A retrospective study intra-operative and postoperative maternal complications of caesarean section during a 10 years period. Eur J Obstet Gynecol Reprod Bio 1997 Jul;74(1):1-6.

2. Leung AS, Leung EK, Paul RH. Uterine rupture after previous caesarean delivery: maternal and fetal consequences. Am J Obstet Gynecol 1993 Oct;169(4):945-950.

3. Miller DA, Chollet JA, Goodwin TM. Clinical risk factors for placenta previa-placenta accreta. Am J Obstet Gynecol 1997 Jul;177(1):210-214.

4. Glazener CM, Abdalla M, Stroud P, Naji S, Templeton A, Russell IT. Postnatal maternal morbidity: extent, causes, 
prevention and treatment. Br JObstet Gynaecol 1995 Apr;102(4): 282-287.

5. Chazotte C, Cohen WR. Catastrophic complications of previous cesarean section. Am J Obstet Gynecol 1990 Sep;163(3):738-742.

6. Godin PA, Bassil S, Donnez J. An ectopic pregnancy developing in a previous caesarean section scar. Fertil Steril 1997 Feb;67(2):398-400.
7. Monteagudo A, Carreno C, Timor-Tritsch IE. Saline infusion sonohysterography in nonpregnant women with previous cesarean delivery: the "niche" in the scar. J Ultrasound Med 2001 Oct;20(10):1105-1115.

8. Lonky NM, Worthen N, Ross MG. Prediction of cesarean section scars with ultrasound imaging during pregnancy. J Ultrasound Med 1989 Jan;8(1):15-19. 
